\title{
CARLOS VILLALOBOS MOLINA
}

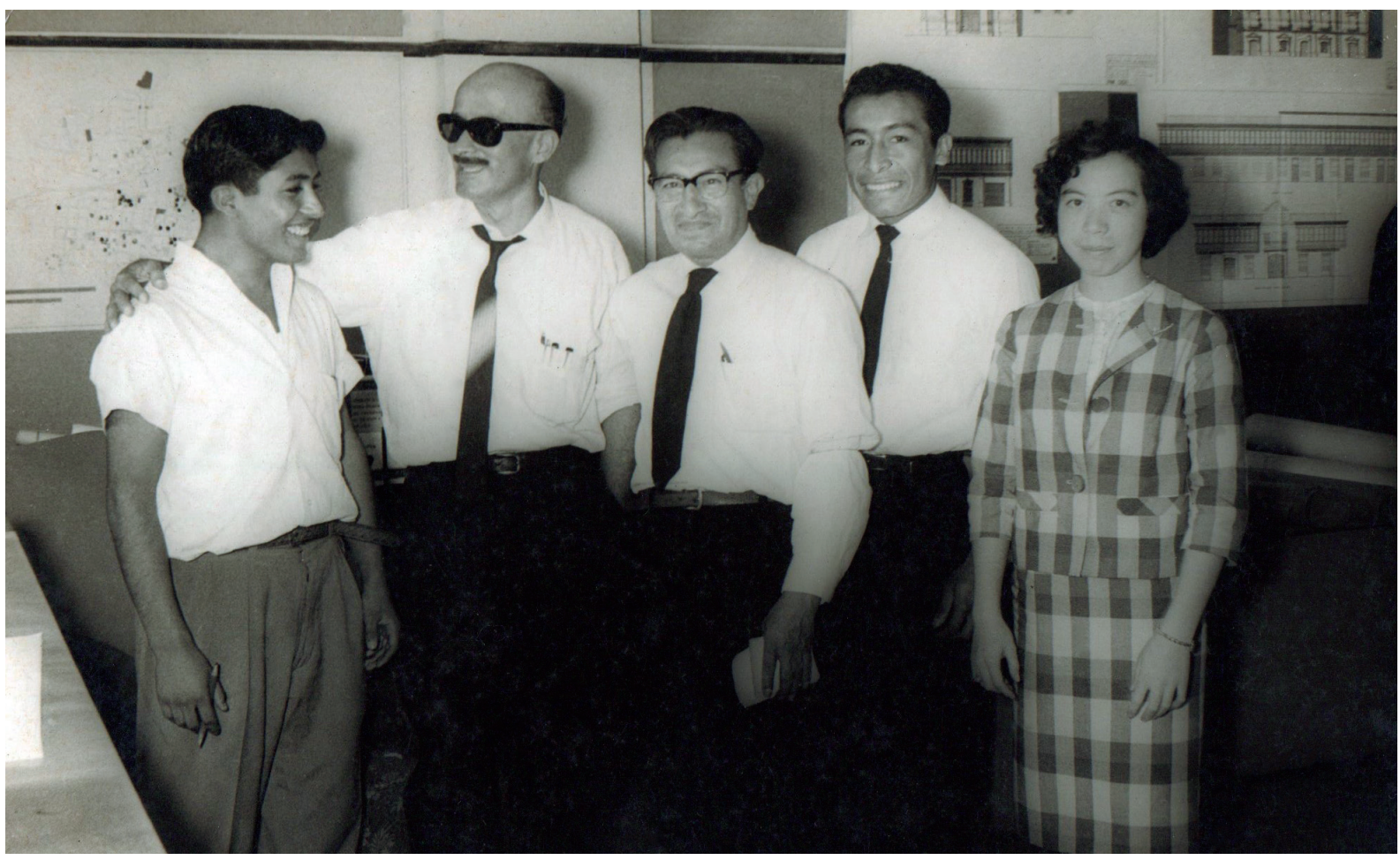

Figura 1. Parte del equipo de dibujantes técnicos quienes trabajaron conmigo en la Junta Deliberante de Monumentos de Lima Metropolitana (1961-1962-1963). De izquierda a derecha: un asistente, técnicos dibujantes, Carlos Villalobos (lentes oscuros), Otárola, Frassinetti, Blanca San.

Fuente: Fotografía por Villalobos Molina, 1962.

Nació en Chosica -Lima, Perú- el 18 de abril de 1916 y falleció a los 100 años el 30 de mayo de 2016.

Autodidacta en dibujo arquitectónico, artístico y técnico, intervino en la elaboración de numerosos proyectos de restauración de monumentos arqueológicos e histórico-artísticos junto con el autor de la presente nota, por ejemplo el Convento de San Francisco de Lima, la Casa Osambela (Lima), la fortaleza Real Felipe (Callao), el conjunto arqueológico Gran Pajatén (San Martín), los restos arquitectónicos de la Villa de Zaña (Lambayeque), la iglesia Conayca (Huancavelica), el Palacio del Almirante (Cusco), la casa del Inca Garcilaso de la Vega (Cusco), la Antigua Casona de San Marcos (Lima), el Monasterio de Santa Catalina (Arequipa), la iglesia de la Compañía (Arequipa), la Casa Vivanco (Ayacucho), la iglesia de la Quinua (Ayacucho), además de otros inmuebles de valor histórico-artístico de las épocas virreinal y republicana, y sitios arqueológicos de nuestro país.

Además, intervino en la elaboración de proyectos de recuperación urbana, entre los cuales destacan el proyecto de restauración del entorno urbano de la Plaza Mayor del antiguo Pueblo de Santiago de Surco, el proyecto de remodelación de la Plazuela San Agustín de Lima y el acondicionamiento urbano de los pueblos de la zona Cusco-Puno del Plan COPESCO. Con el autor de este texto, colaboró en el Consejo Nacional de Monumentos; la Junta Deliberante Metropolitana de Monumentos Históricos, Artísticos y Lugares Arqueológicos de Lima; el Plan COPESCO; y la Corporación de Turismo del Perú, entre las entidades más importantes. Previamente trabajó con ilustres arquitectos, tales como Ricardo de Jaxa Malachowski, Guillermo Payet, Enrique Seoane Ros, Héctor Velarde y José García Bryce. Entre las entidades más remarcables colaboró profesionalmente con las empresas Graña y Montero, Utah Pacific Ltd. y Southern Perú, además del Ministerio de Fomento y Obras Públicas. 


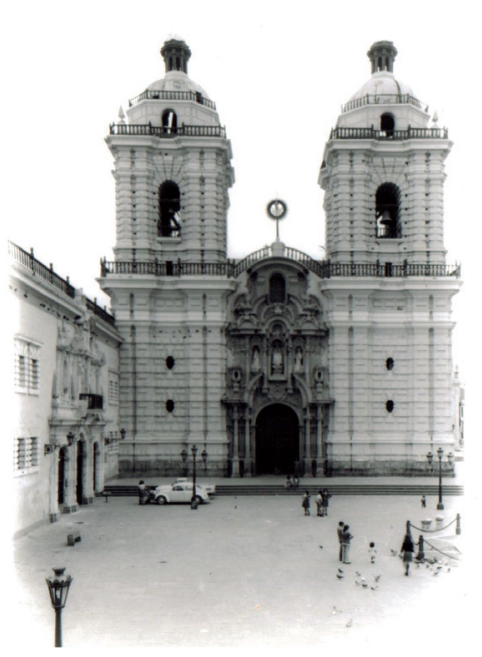

Figura 2. Iglesia de San Francisco el Grande, Lima. A la izquierda, el ingreso al convento. En la parte superior de este volumen, la biblioteca que contiene valiosos incunables

Fuente: Fotografía por Villalobos Molina, 1970.
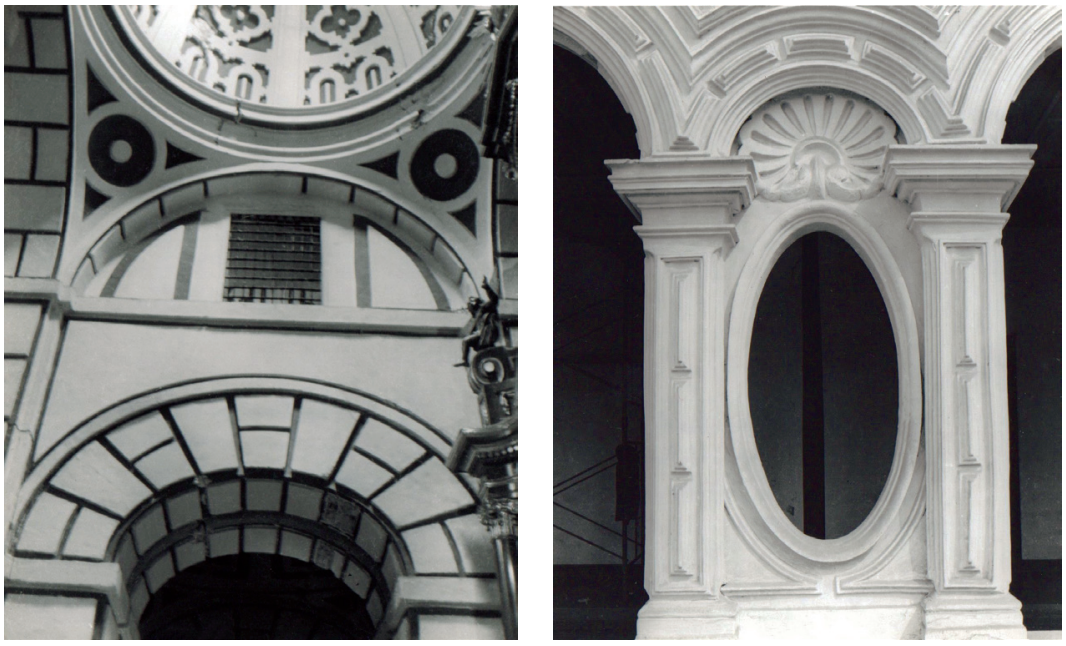

Figura 3. Interior de la Iglesia de San Francisco El Grande, Lima. Se aprecia un sector de las pechinas y la cúpula

Fuente: Fotografía por Villalobos Molina, 1970.
Figura 4. Óculo en uno de los intercolumnios de la galería superior del claustro mayor del Convento de San Francisco El Grande, Lima

Fuente: Fotografía por Villalobos Molina, 1970.

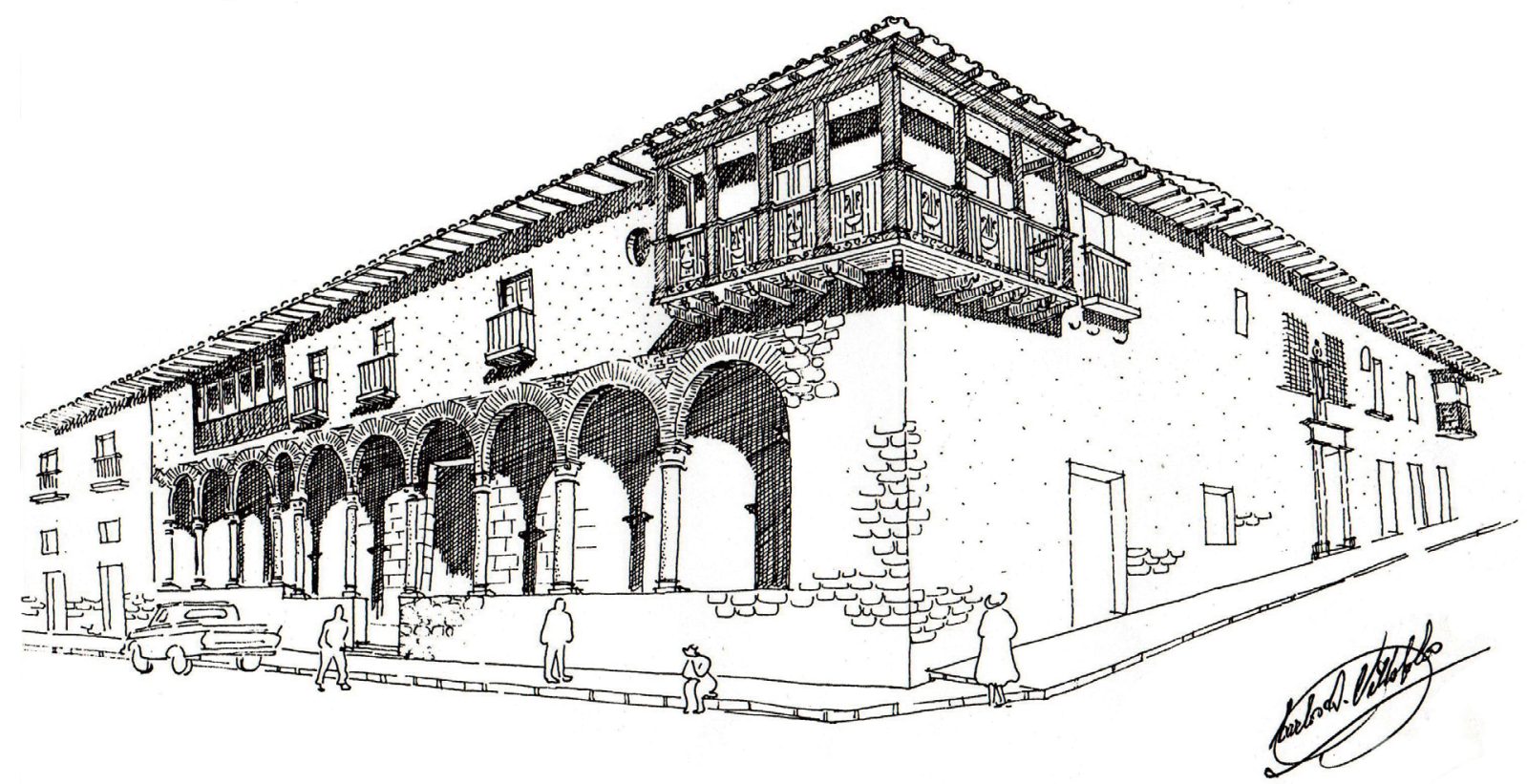

Figura 5. Perspectiva de la casa natal del ilustre cronista mestizo Inca Garcilaso de la Vega - Cusco

Fuente: Dibujo por Villalobos Molina, 1967. 


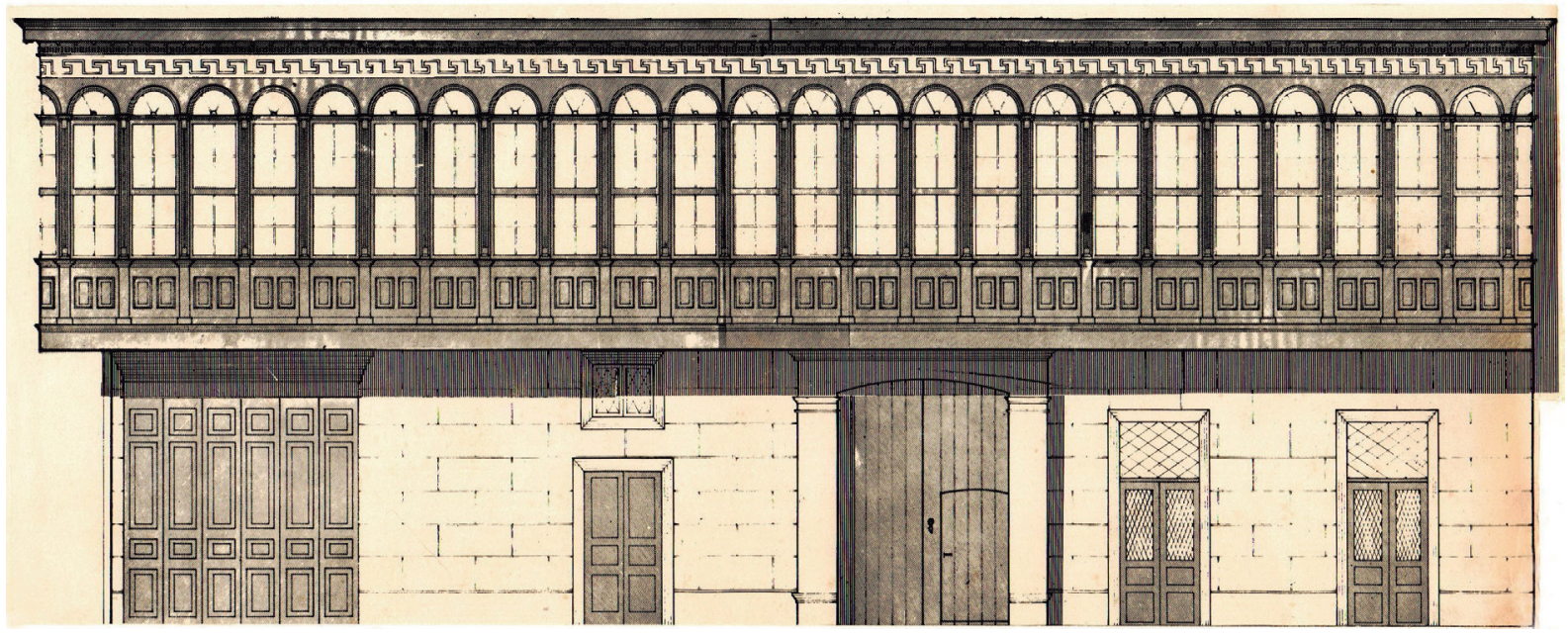

Figura 6. Elevación del local del antiguo Conservatorio Nacional de Música - Lima Fuente: Dibujo por Villalobos Molina, 1970.

En mi carrera profesional, sobre todo en el campo de la investigación, y la elaboración de proyectos de conservación y restauración de monumentos arqueológicos e histórico-artísticos, tuve el privilegio de contar con el invalorable apoyo de los llamados técnicos, que en realidad son auténticos profesionales en sus respectivos campos de acción. Aquí me refiero solamente a tres de ellos: Abraham Guillén, fotógrafo; Pedro Rojas Ponce, fotógrafo y dibujante; y Carlos Villalobos, dibujante técnico. A todos ellos mi gratitud. En vida solamente pude rendir homenaje a Abraham Guillén y a Carlos Villalobos Molina, al primero mediante una amplia exposición de sus obras fotográficas expuesta en los salones del Museo de Arte Italiano, y al segundo mediante la entrega de un Diploma de Honor del Fondo Cultural Documental de la Arquitectura y el Urbanismo (FONCULDAU), el cual expresa nuestro agradecimiento y felicitación por su valiosa contribución a nuestro patrimonio cultural documental de la arquitectura y el urbanismo, principalmente compuesto por la expresión gráfica y fotográfica de numerosos proyectos de restauración de monumentos arquitectónicos del Perú. Don Carlos Villalobos Molina también fue un excelente fotógrafo, como puede observarse en las Figuras 2, 3 y 4.

En el salón Garcilaso del Hotel de Turistas del Cusco, presenté una primera propuesta de intervención restauradora del inmueble donde nació precisamente nuestro ilustre cronista mestizo el Inca Garcilaso de la Vega, donde el Señor Carlos Villalobos colaboró en los diseños. Luego del diagnóstico exhaustivo del inmueble se llegó a la versión final que luego se aplicó en obra.

Un ejemplo representativo de la calidad de su trabajo se puede observar en el Centro de Documentación de Arquitectura Latinoamericana (CEDODAL), ubicado en Buenos Aires (Argentina), institución que dirige el distinguido arquitecto Ramón Gutiérrez. Allí existe valiosa información, conservada en su archivo documental. En uno de sus prestigiosos boletines informativos se remarca la sección "Colecciones Especiales", que se ha formado a partir de donaciones y adquisiciones, y se mantiene sistemáticamente, cualquiera sea la índole del material documental que las integre. Entre ellas cabe destacar los archivos de Martín Noél, Enrique Marco Dorta y Ricardo J. Alexander, así como el material documental copiado de los fondos de Mauricio Cravotto y Héctor Velarde. En este excepcional repositorio documental se alberga buena parte de la producción de Don Carlos Villalobos (Figuras 5 y 6 ).

Para finalizar, deseo compartir este testimonio, suscrito por el mismo Sr. Carlos Villalobos a sus 96 años de edad, donde evidencia todo un compromiso de vida entregado al patrimonio monumental peruano. 


\section{A MIS 96 AÑOS}

Durante mi actividad profesional he tenido la oportunidad como técnico especializado en levantamientos de monumentos arquitectónicos de nuestro país laborar con el Arq. Víctor Pimentel, desde los primeros años de la década del 60 hasta mediados del 75.

Esta actividad me ha permitido intervenir bajo la Directiva del Arq. Victor Pimentel en importantes monumentos históricos del Perú como la Casa de Garcilaso de la Vega y el Palacio del Almirante en Cusco, el Convento de San Francisco en Lima, y muchos otros, además tuve la ocasión de trabajar con el Arq. Víctor Pimentel en diferentes instituciones oficiales relacionadas a nuestro patrimonio cultural en inmuebles tales como:

El Consejo Nacional de Monumentos, La Junta Deliberante Metropolitana de Lima de Monumentos, la Corporación de Turismo del Perú, ocasión esta última en lo que ha pedido del Arq. Victor Pimentel integré el grupo de expedicionarios que bajo su mando se realizaron en los años 1965 y 1966 al sitio Arqueológico llamado El Gran Pajatén que habían puesto al descubierto algunos indicios de este importante lugar arqueológico un grupo de pobladores de Pataz en el Dpto. de La Libertad guiados por el Sr. Carlos Torrealba.

Es mi deseo dejar este testimonio del privilegio de haber trabajado con el Arq. Víctor Pimentel en muchas otras obras de restauración de nuestro patrimonio arqueológico histórico y artístico.

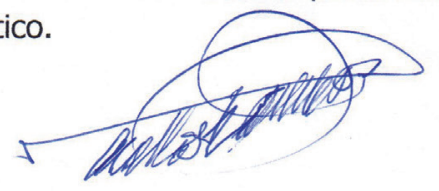

13 de Agosto del 2014

Carlos Alberto Villalobos Molina

Figura 7. Testimonio de Carlos Villalobos a los 96 años de edad

Fuente: Archivo Carlos Villalobos, 2014. 